DOI: $\underline{10.20472 / E S .2018 .7 .1 .003}$

\title{
HAVING GOOD FRIENDS IS A GOOD THING: THE EFFECTS OF PEERS AND SUPERSTARS ON PERFORMANCE IN SWIMMING COMPETITIONS
}

\author{
WEN-JHAN JANE, JIA-LING YAO, JYE-SHYAN WANG
}

\begin{abstract}
:
By exploiting an unusually rich panel data set from the National Database of Student Athletes, this article addresses the issue of peer effects and superstar effects on performance in multi-stage swimming competitions. Four key findings are presented. First, the evidence from relay teams supports a positive inter-team peer effect from competitors in a male relay race, but a negative inter-team peer effect from competitors in a female relay race. Second, the evidence from both female and male relay teams shows that there exists a positive intra-team peer effect from teammates. In our estimations for female relay races, a foolish teammate does more harm $(+3.11$ seconds) than a brilliant opponent does good ( +0.55 seconds) in the estimation of the Heckman Selection Model based on panel data. Third, a male team with average-quality swimmers performs better than a team with dispersed-quality swimmers. Fourth, for the super-team effects in these tournaments, on average, the female relay teams' (/male relay teams') times are approximately 2.85(/2.09) seconds faster/slower when the previous year's winning team participates.
\end{abstract}

\section{Keywords:}

Heterogeneous tournaments; Multi-stage tournaments; Peer effects; Superstar effects

JEL Classification: J13, J18, L83

\section{Authors:}

WEN-JHAN JANE, Department of Economics, Shih Hsin University, Taiwan, Email:

krisenwerk@gmail.com

JIA-LING YAO , Department of Economics, National Taiwan University, Taiwan, Email: a911277@gmail.com

JYE-SHYAN WANG , Department of Physical Education, National Taiwan Normal University, Taiwan, Email: jyeshyan@ntnu.edu.tw

\section{Citation:}

WEN-JHAN JANE, JIA-LING YAO , JYE-SHYAN WANG (2018). Having Good Friends is a Good Thing: The Effects of Peers and Superstars on Performance in Swimming Competitions. International Journal of Economic Sciences, Vol. VII(1), pp. 39-64., 10.20472/ES.2018.7.1.003 


\section{INTRODUCTION}

In many circumstances, the decision of agents to exert effort in education or some other activity cannot adequately be explained by their characteristics or by the intrinsic utility derived from the activity. Rather, its rationale may be found in how peers and others value this activity. There is indeed strong evidence to show that the behavior of individual agents is affected by that of their peers. Most of this literature is concerned with examining how peers and environmental factors affect youth behavior with regard to their educational achievements, health, criminal involvement, fertility, etc. (for surveys, see Glaeser and Scheinkman, 2001; Moffitt, 2001; Durlauf, 2004; loannides and Loury, 2004; loannides, 2012).

Moreover, several selection processes use multi-stage tournaments to choose the best candidates. The theoretical models predict that tournaments are efficient in selecting the best candidates (Rosen, 1986; Brown, 2011). Due to the scarcity of data on the agents involved in these selections, the empirical evidence is limited. Meanwhile, few empirical studies have demonstrated that individuals in tournament-type contests perform less well on average in the presence of superstars (Brown, 2011). This paper differs from previous studies in that it looks at the effects of peers and superstars on swimming performance at the same time in multi-stage competitions.

By exploiting an unusually rich panel data set derived from the National High School Athletic (NHSA) games in Taiwan, this paper investigates whether positive or negative peer effects exist for swimmers. To assess whether swimmers experience peer effects, we estimate various empirical models that relate team performance in a team relay to the average quality of their competitors and teammates, as well as their distribution in a race. The results suggest that as the average competitor quality increases, i.e., competitors' average times in previous races decrease, a male relay team's performance improves, but a female relay team's performance worsens. This evidence supports the view that a positive peer effect exists in the male races and that a negative peer effect exists in the female races.

Moreover, as the average teammate quality increases, i.e., the teammates' average times in previous races decrease, team performance improves in both female and male relay races. This evidence supports the view that a positive effect exists among members in a relay team. In addition to the results of peer effects among relay competitors, we conclude that having good teammates is a good thing in swimming relays. 
In a relay race, as the distribution of the teammates' quality increases, i.e., the standard deviation of the teammates' time in previous races increases, a male relay team's performance worsens, but a female relay team's performance improves. The former evidence indicates that a disparity of quality among teammates weakens a male swimming team's performance; the latter evidence indicates that an equality of quality among teammates reduces a team's performance in a relay competition.

Finally, as for the super-team effects in these competitions, a female swimming team swims faster when a team that was the previous year's winning team participates, relative to when such a team is absent. The finding indicates that large ability differences in swimming teams are associated with better performance. The presence of a superstar team inspires other competitors to try their best. The effect is opposite to that based on Brown's (2011) findings for the Professional Golfers' Association (PGA).

This article is different from Jane (2015) and the differences are two-fold. Firstly, Jane (2015) focuses on the peer effects on performance within individual swimming teams, but this paper addresses the peer effects both within a team and between teams. Secondly, a growing body of empirical studies on superstar effects has found that the presence of a high-ability player is associated with reduced performance (e.g., Brown, 2011). Therefore, we include a discussion on superstar effects.

Understanding peer effects within a group and between competitors is the first step towards learning how to best structure situations in which competition exists among players of heterogeneous ability. The NHSA dataset provides a considerable number of observations based on swimmers' performance. By matching these performance data with swimmers' characteristics, the estimations of marginal effects for swimmer's characteristics can provide valuable information for players and coaches. Moreover, economic decision making regularly involves strategic interactions within teams of heterogenous contestants. Just like workers face promotion tournaments with incentive systems that involve strategic decisions about effort provision, the relay teams face the same decision environments with incentive systems. ${ }^{1}$ The remainder of this paper is organized as follows: Section 2 provides a short overview of the relevant literature. The data and the empirical methodology are considered in Section 3. The results are presented and discussed in Section 4, and the paper ends with a summary of the main conclusions.

\section{LITERATURE REVIEW ON PEER EFFECTS AND COMPETITIONS}

Production generally occurs in groups where group members work as a team to

\footnotetext{
1 The reactions of contestants to incentives, contest design and contestants' heterogeneity has been a central focus of the theoretical literature (Lazear and Rosen, 1981; Baik, 1994; Stracke et al., 2015).
} 
produce goods or services. In this kind of environment, individual productivity typically depends on the attributes of the individuals' characteristics such as education and experience as well as those of their peers. That is, a high level of performance by a given individual generates positive externalities that induce other people to perform better, or a lower level of performance of such an individual causes other people to follow suit. The phenomenon is an example of a peer effect in an organization.

In theory, the effect of an individual's productivity on her peers can be either positive or negative. On the one hand, higher teammate productivity may result in less effort, if the presence of more productive teammates induces an individual to free-ride. On the other hand, higher teammate productivity may result in higher effort because of learning, social pressure, leading-by-example, or imitation. Therefore, coworkers can significantly impact each other's productivity. These peer effects may either be positive through teammates' mutual learning (e.g., Berg, Appelbaum, Bailey, \& Kalleberg 1996; Hamilton, Nicherson, \& Owan 2003, 2012; Lucas 1988) and complementarities in skills and abilities (e.g., Boning, Ichniowski, \& Shaw 2007; Ichniowski, Shaw, \& Gant 2002; Prat 2002), or negative due to the reduced effort of free-riding (e.g., Holmstrom 1979; Carpenter 2007) and production externalities from other co-workers (e.g., Holmstrom 1982).

The growing body of empirical studies on peer effects has consistently found that peer quality can positively affect worker productivity. Mas and Moretti (2009), for example, show that, under hourly wages, supermarket checkout workers work faster while in the line of sight of a high-productivity worker because of social pressure. Franck and Nüesch (2010) find that the talent disparity among the entire squad improves a team's final standing in the German soccer championship race in the long run, that is, a highly-talented player has a positive effect on the relatively less-talented players' performance. Then, Depken and Haglund (2011) find that team member quality improves team performance, but at a decreasing rate in the NCAA $4 \times 400 \mathrm{~m}$ men's relay teams. All of their results support the view that a high-ability teammate has a positive effect on his or her peers. ${ }^{2}$

Some important issue concerns whether male and female cope with stress in athletic settings in dissimilar ways. Research supports propositions that the gender difference in competitiveness accounts for a substantial portion of the gender difference in track choice (Buser et al., 2014; Croson \& Gneezy, 2009; Niederle \& Vesterlund, 2011).

\footnotetext{
2 Similarly, Azoulay, Zivin, and Wang (2010) find that deaths of academic superstars lead to declines in co-authors' publication rates. Ichino and Maggi (2000) find that absenteeism and episodes of misconduct are considerably more frequent in the southern branches of a bank. They demonstrate the impact of peers in terms of negative productivity (absenteeism) among Italian bank workers, and show that an individual's shirking level increases with his coworkers' average shirking level.
} 
According to both cognitive anxiety and self-confidence are significantly related to competitive sport performance. Woodman \& Hardy (2003) conclude that men have significantly higher mean effect sizes for cognitive anxiety than women. Female is more likely to seek social support and to use emotion focused strategies than male (Carver et al., 1989; Ptacek, Smith, \& Zanas, 1992; Stone \& Neale, 1984). The performance of females reported using higher levels of seeking social support for emotional reasons and increasing effort (Peter \& Thomas, 1995; Astor-Dubin \& Hammen, 1984; Ptacek et al., 1992). Those findings are consistent with performance-related stress in sport that females and males cope differently.

Conversely, three studies using data from academic superstars and professional golf tournaments are exceptions to these findings. Guryan, Kroft, and Notowidigdo (2009) find no evidence that a player's performance is affected by the existence of high-ability players (star players), while Brown (2011) documents that the presence of a high-ability player (Tiger Woods) is associated with reduced performance from peers. On average, more highly-skilled PGA golfers' first-round scores are approximately 0.2 strokes higher when Tiger Woods participates, relative to when Woods is absent. The overall superstar effect for these tournaments when Tiger Woods participates is approximately 0.8 strokes. ${ }^{3}$

Swimming competitions are composed of multi-stage contests. An important branch of research in this area is devoted to understanding the relationship between individual behavior/effort and competitions (Ehrenberg \& Bognanno, 1990; Becker \& Huselid, 1992; Main, O'Reilly, \& Wade, 1993; Eriksson, 1999; Sunde, 2009; Genakos \& Pagliero, 2012). Ehrenberg and Bognanno (1990) and Becker and Huselid (1992) use data from sports tournaments to study the link between prizes and performance. Main, O'Reilly, and Wade (1993) and Eriksson (1999) study corporate tournaments and executive compensation. Sunde (2009) tests for financial incentive effects on effort using data from the final two rounds of the Grand Slam and Masters Series tournaments in men's professional tennis. Genakos and Pagliero (2012) analyze data from weightlifting competitions and find that the athletes who lag behind (underdogs) take more risk and exert more effort than the favorites. However, the more risk the subjects take, the lower is their probability of succeeding in the round.

Early models of tournaments rely on the assumption that players have equal ability (Lazear \& Rosen, 1981). Subsequent theoretical analysis and empirical research has examined tournaments in which competitors have heterogeneous abilities (Knoeber and Thurman, 1994), including recent work on the effect of completely dominant

\footnotetext{
${ }^{3}$ Brown (2011) provides a simple formal model of the effects of incentives and strategies created by the presence of a superstar in a professional sports setting.
} 
competitors (Brown, 2011). Evidence of superstar effects, in which players perform less well in the presence of a much superior player, has been found in competitive sporting environments such as tennis (Sunde, 2009; Lallemand, Plasman, \& Rycx, 2008), and indeed in the case of professional golf in the US (Brown, 2011) and Japan (Tanaka and Ishino, 2012).

The swimmers' data have two advantages when investigating peer effects in sequential competitions. First, the setting of the contest is close to that of real world tournaments. Just like workers and students who take part in parallel tournaments, all the swimmers obtain the same information regarding the others' quality and performance at the same time. Second, in a way that differs from runners and golfers (Depken \& Haglund, 2011; Brown, 2011), the "experimental conditions" are more stable in a swimming pool than outside. Runners and golfers are exposed to different intensities and directions of wind, and at the same time they can hear the supporters cheering for or against them. These factors may affect the final results in unobservable ways, which are not captured in extant studies. Therefore, the goal of this paper is to employ data on swimming competitions for individual and relay items from the NHSA games to investigate some further evidence of peer effects and superstar effects in competitions.

A recent study has found direct evidence of positive peer effects in junior high school athlete swimming competitions. The research noted by Jane (2015) uses the same database from 2008-10, but is confined to investigating peer effects on swimmer's performance in individual swimming competitions. This work builds on the previous piece by investigating peer effects both within a team and between teams. Understanding the intra-team and inter-team peer effects is important to human resource management, and it also provides valuable information for race organizers and coaches.

\section{EMPIRICAL METHODOLOGY AND DATA DESCRIPTION}

The NHSA competition is the largest multi-sporting event for junior and senior high school athletes in Taiwan. The National Database of Student Athletes (NDSA) has collected approximately 1,934,000 athletes' demographic characteristics and performance records in NHSA games from 2007 to 2015. The database includes all swimming, track and field, gymnastic, table tennis, badminton, tennis, kickboxing, judo, archery, karate, and soft tennis athletes in the NHSA Games. It is a rare set of micro-data and is suitable for studies on peer effects.

As for the NHSA swimming competitions, there are individual and relay races. Individual races consist of freestyle, breaststroke, backstroke, and butterfly. Races 
cover 50,100, 200, 400, 800, and 1500 meters. ${ }^{4}$ Relay races consist of $4 \times 100 \mathrm{~m}$ freestyle, $4 \times 200 \mathrm{~m}$ freestyle, and $4 \times 100 \mathrm{~m}$ medley relays. Each of the short-distance and long-distance competitions has two stages - heats and finals. Therefore, the competitions allow the possibility to observe whether the effort in the initial stage of the competition is a reliable signal of the effort lavished on the last step.

The swimming teams for each county were selected from athletes with higher scores of junior and senior high school swimming competitions, the teams paired for races based on preliminary score. The competitors are placed in preliminary based on their times in order. Within a preliminary the fastest swimmer is in the middle. In the competition with the 8 lanes, teams will be assigned in this order from fastest to slowest 4, 5, 3, 6, 2, 7, 1, and 8 .

In this paper, all of the data cover 3 types of relay races and are provided by the Ministry of Education for research purposes. The dataset contains extensive personal characteristics and yearly performance information on competitors from 2008 to 2010 . Demographic data include age, gender, height, and weight. Competition dates and locations, as well as the swimmers' schools are also included in the dataset.

\subsection{Empirical Methodology}

To test for a positive or negative peer effect on team performance, the relay team production function is constructed as shown in equation (1).

$$
P=\alpha_{0}+X_{1} \alpha_{1}+\varepsilon 1,
$$

where $P$ is the relay team's performance, and $\varepsilon_{1}$ is an error term. $X_{1}$ includes a measure of relative quality for peers, superstars, competitors' characteristics, and environmental factors for the relay team's analyses. More specifically, both the average and standard deviation of participant quality in a race are used in these functions.

The inter-team and intra-team quality is measured according to Depken and Haglund (2011) in their context of NCAA running relay teams. The estimated model for the relay team production function can be specified as equation (2):

$$
\text { Time }_{i t}=\beta_{0}+\beta_{1} \text { AvgTime }_{-\mathrm{it}-1}+\beta_{2} \text { AvgTime }_{\mathrm{it}-1}+\beta_{3} \text { SDTime }_{\mathrm{it}-1}+\beta_{3} \mathrm{Star}_{\mathrm{t}}+\mathrm{X}_{\mathrm{i}} \Phi+\varepsilon_{\mathrm{it}} \text {, }
$$

where Timeit is the number of seconds a relay team takes to complete the $4 \times 100 \mathrm{~m}$ freestyle, $4 \times 200 \mathrm{~m}$ freestyle, and $4 \times 100 \mathrm{~m}$ medley relays, and the $\beta$ 's and $\Phi$ are parameters to be estimated. The explanatory variables include the average number of

\footnotetext{
${ }^{4}$ See Jane (2015) for the details.
} 
seconds taken by competitor teams which excludes team $i$ in the previous race (AvgTime-it-1); the average number of seconds taken by a particular team's members in the previous race (AvgTime it-1) $^{\text {) }}$ the standard deviation of the number of seconds taken by the team's members in the previous race (SDTimeit-1); a dummy for the presence of a superstar relay team (Star, yes $=1$, otherwise $=0$ ); and environmental factors $\left(X_{i}\right)$. AvgTime $_{i t-1}$ is used to measure the intra-team peer effects, and AvgTime ${ }_{\text {-it- } 1}$ is used to measure the inter-team peer effects. Control variables include the swimmers' average height (Height), average weight (Weight), and average age (Age) in a team. Environmental factors $X_{i}$ like dummies for the race types (RaceType), year dummy (Year), and a dummy for whether the race is a preliminary race (PRELIMS, yes=1, otherwise $=0$ ) are also included.

\subsection{Single-elimination Competitions and Sample Selection Bias}

To mathematically represent the problem of selection bias, one must think about when we observe values for equation (1) and when we do not. Because swimmers are decided by the single-elimination competitions, we can develop a selection rule as follows - we only observe the number of seconds taken by a relay team in a particular contest (Timeit) if their expected winning percentage from entering is greater than or equal to the threshold of promotion into the next round (WP*). Let us assume that the $i^{\text {th }}$ relay team's winning percentage $\left(E W P_{i t}\right)$ is

$$
E W P_{i t}=X_{2, i t \alpha_{2}}+\varepsilon_{2, i t}
$$

where the vector $X_{2, \text { it }}$ contains measures of swimmer skill, swimmer characteristics and tournament specific variables (e.g., RaceType et al.) in a relay team. To understand how this selection rule impacts our estimates for swimmer performance (Time it), we must first think about how we would discuss this relationship if there were no selection rule. For unbiased estimates, we expect that the conditional expectation of the $i^{\text {th }}$ relay team's number of seconds in a tournament looks like (4):

$$
E\left(\text { Timeit }_{i t} \mid X_{1, i t}\right)=X_{1, i t} \alpha_{1},
$$

However, given our sample selection rule it is actually as in (5):

$$
E\left(\text { Time }_{\text {it }} \mid X_{1, i t}, E W P \geq W P^{*}\right)=X_{1, \text { it }} \alpha_{1}+E\left(\varepsilon 1, \text { it } \mid E W P \geq W P^{*}\right),
$$

Because of potential omitted variable bias, it is this second term that gives us trouble if the conditional expectation of $\varepsilon$ 1it is not zero.

Given that selection into tournaments is nonrandom, one should see that the conditional expectation for $\varepsilon_{1 \text { it }}$ is nonzero, which implies that the coefficients in $\alpha_{1}$ will 
be biased. In the context of this analysis, if any of the characteristics that affect a relay team's performance also affect their chance of entering a given tournament, then OLS estimates using equation (1) will be biased.

When one uses least squares to analyze data plagued by selection bias, the missing observations may cause biased estimates because the error term is correlated with the probability of an individual either participating in the tournament or being recorded as having participated in the tournament. For example, all swimmers compete with each other in the single-elimination competitions. That may cause that swimmers do not choose randomly but picked up swimmers that are similar. Heckman's two-stage estimator is most widely used approach to selection bias, the implementation requires the researcher to understand the source and magnitude of the bias. Heckman's (1979) procedure calls for one to first estimate, using a selection equation, the effect that individual characteristics have on the probability of the individual participating in a tournament and therefore being recorded in the data.

\subsection{Data Description}

The data contain information for 3,232 player records and their personal characteristics for the swimming relay teams over the 2008-2010 NHSA Games. Variable descriptions and corresponding statistics are listed in Table 1. The average number of seconds in a female relay race is 371.29 , and the average number of seconds in a male relay race is 332.92 . The fastest relay team is from a famous swimming school, i.e., the Taipei Municipal Nan Gang High School (NGHS), and the record for these males is 213.96 seconds in the final of a $4 \times 100 \mathrm{~m}$ freestyle relay in 2008. The worst record is 671.76 seconds, and it belongs to a team of 15 -year-old females who participated in a preliminary $4 \times 200 \mathrm{~m}$ freestyle relay in 2010 .

A last-year champion school participated in $29 \%$ of this year's races in male relay races, and a last-year champion school participated in $23 \%$ of this year's races in female relay races. The average swimmer's age in a relay team during this period was 15.84 for females with a range from 13.25 to 19 , and $46 \%$ players were female. The average male swimmer's height in a team was 172.92 centimeters, and the average male swimmer's weight was 65.19 kilograms. 
Table 1 Descriptive Statistics of the Data $(n=3,232)$

\begin{tabular}{ll}
\hline Variable & Description \\
\hline Male & $(\mathrm{n}=1,736)$ \\
TimeTeam & Team's seconds in a relay race \\
Proxies of Peer Effects \\
AvgTime $_{\text {-it-1 }}$ & Average seconds of team competitors \\
& which excluded team i in the previous race \\
AvgTime $_{\text {it-1 }}$ & $\begin{array}{l}\text { Average seconds of teammates in team i } \\
\text { in the previous race }\end{array}$ \\
SDTime $_{\text {it-1 }}$ & $\begin{array}{l}\text { Standard deviation of teammates' seconds } \\
\text { in the previous race }\end{array}$
\end{tabular}

$332.2445 \quad 124.1777 \quad 225.4115$

536.405

102.406938 .86318

54.7

160.18

$2.018623 \quad 2.348938 \quad 0.021223$

13.52695

Control variables

Star $_{1}$

Dummy of a last-year winning team's

Age

Height $(\mathrm{cm})$

Weight $(\mathrm{kg})$

PRELIMS

Female

TimeTeam

Proxies of Peer Effects

AvgTime $_{\text {-it-1 }}$

Avg Time $_{\text {it }-1}$

SDTime $_{\text {it-1 }}$

Control variables

Star 1

Age

Height $(\mathrm{cm})$

Weight $(\mathrm{kg})$

PRELIMS participation

Swimmer's average age in a team

Swimmer's average height in a team

Swimmer's average weight in a team

Dummy of preliminary (yes $=1$, otherwise $=0$ ) $(n=1,496)$

Team's seconds in a relay race

Average seconds of team competitors which excluded team $i$ in the previous race

Average seconds of teammates in team $i$ in the previous race

Standard deviation of teammates' seconds

in the previous race

$0.288923 \quad 0.453438$

0 1

$\begin{array}{lll}16.04378 & 1.435368 & 13.25\end{array}$ 19

$172.9188 \quad 4.226369$

142 187

$65.19297 \quad 5.498851$

48.25

$0.709677 \quad 0.454042$

0 81

1

$371.2908 \quad 138.5509 \quad 240.26$

671.76

$\begin{array}{llll}367.0409 & 135.1537 & 250.4711 & 580.3575\end{array}$

$\begin{array}{llll}112.1326 & 41.28578 & 59.57 & 174.19\end{array}$

$\begin{array}{llll}6.385968 & 12.8876 & 0.247489 & 56.68866\end{array}$

$\begin{array}{llll}0.227674 & 0.419537 & 0 & 1\end{array}$

$\begin{array}{llrr}15.8369 & 1.474069 & 13.25 & 19\end{array}$

$\begin{array}{llll}162.4586 & 3.02755 & 155.25 & 170\end{array}$

$\begin{array}{llll}54.30749 & 3.744395 & 44.25 & 63.5\end{array}$

$\begin{array}{lll}0.641711 & 0.479658 & 0\end{array}$

In equation (2), for the inter-team peer effects, the coefficient of AvgTime-it-1 is expected to exhibit a positive relationship with Time $i$, if there exists a positive 
inter-team peer externality in a swimming competition. Conversely, if the peer externality's impact on a team's performance is negative, the coefficient of AvgTime-it-1 is expected to be negative. As to the intra-team peer effects, the coefficient of AvgTime $_{\text {it- } 1}$ is expected to exhibit a positive relationship with Time it, $_{\text {, }}$ if there exists a positive peer externality in a swimming team. Conversely, if the peer externality's impact on a team's performance is negative, the coefficient of AvgTime it- 1 is expected to be negative.

As for the coefficient of SDTime $i t-1$, if the coefficient is positive, it means that a dispersed-human-capital team induces more seconds. Therefore, a race with members with average talent has better individual performance. This indicates that an average-human-capital race benefits from positive peer effects. Conversely, if the coefficient is negative, an average-human-capital race suffers from negative peer effects.

Regarding the control variables, according to the literature on the relationship between a swimmer's somatotype and performance, the coefficients of Height and Gender are expected to be negative, and the coefficient of Weight is insignificant (see, i.e., Helmuth, 1980; Blanksby, Bloomfield, Ponchard, \& Ackland, 1986; Mei, 1989; Geladas, Nassis, \& Pavlicevic, 2005; Jane, 2015).

\section{EMPIRICAL RESULTS AND DISCUSSION}

Before performing our analysis of the peer effects, multi-stage contests are employed to investigate the different types of behavior in these competitions. Table 2 displays the results of the average times of the high school females and males at the end of each stage in the contests. All values in the t tests reject the null hypothesis of mean equality for a two-sample comparison. The average time in the preliminaries is much higher than in the finals. It shows that high school females (sensibly) perform worse in the preliminaries than in the finals. In addition, the same pattern emerges when males in the preliminaries and finals are compared. The results suggest that effort increases during the passing from one stage to the next. The evidence corresponds to previous findings (e.g., Ehrenberg \& Bognanno 1990; Sunde 2009; Genakos \& Pagliero 2012). 
Table 2 Average Times of the High School Females and Males at the End of Each Stage in the Tournaments

\begin{tabular}{|c|c|c|c|}
\hline Event & Preliminaries & Finals & Significance \\
\hline \multicolumn{4}{|l|}{ Females } \\
\hline $4 \times 100$ meters & 260.346 & 252.594 & $* \star \star$ \\
\hline freestyle & $(0.799)$ & (0.913) & \\
\hline $4 \times 200$ meters & 569.078 & 551.580 & $* \star *$ \\
\hline freestyle & (1.808) & $(1.580)$ & \\
\hline $4 \times 100$ meters & 293.276 & 284.086 & $* * *$ \\
\hline medley relays & (1.096) & $(1.254)$ & \\
\hline \multicolumn{4}{|l|}{ Males } \\
\hline \multirow{2}{*}{$\begin{array}{l}4 \times 100 \text { meters } \\
\text { freestyle }\end{array}$} & 230.179 & 224.300 & $* * *$ \\
\hline & $(0.498)$ & $(0.841)$ & \\
\hline \multirow{2}{*}{$\begin{array}{l}4 \times 200 \text { meters } \\
\text { freestyle }\end{array}$} & & & $* \star *$ \\
\hline & (1.174) & (1.874) & \\
\hline \multirow{2}{*}{$\begin{array}{l}4 \times 100 \text { meters } \\
\text { medley relays }\end{array}$} & & 5 & $* * *$ \\
\hline & $(0587)$ & $(1327)$ & \\
\hline
\end{tabular}

Notes: $(a)^{\star \star *}$ denotes significance at the $1 \%$ level.

(b) Values in parentheses are the standard errors.

For the analysis of the effect of the presence of a superstar on swimming performance, a swimming relay team that was ranked first last year is defined as a superstar. All values of the $t$ tests in Table 3, including the tests of the average times of the high school students both with and without a superstar relay team in the competitions, reject the null hypothesis of mean equality for the two-sample comparison. That is, these swimming teams perform significantly better in races with a superstar team. Differing from the negative effect of a superstar's presence in Brown (2011), this evidence supports a significant difference in the average times between student 
athletes both with and without a superstar team in the swimming relays. ${ }^{5}$ However, the figures in Tables 2 and 3 are not under the condition of other things being equal, and further empirical analysis is needed to clarify the results.

Table 3 Average Times of the High School Females and Males with and without a Star in the Tournaments.

\begin{tabular}{|c|c|c|c|}
\hline Event & With a star & Without a star & Significance \\
\hline \multicolumn{4}{|l|}{ Females } \\
\hline \multirow[t]{2}{*}{$4 \times 100 m$ freestyle relay } & 257.857 & 264.138 & *** \\
\hline & $(0.727)$ & $(0.944)$ & \\
\hline \multirow[t]{2}{*}{$4 \times 100 m$ medley stroke relay } & 290.676 & 299.957 & $* * *$ \\
\hline & $(0.987)$ & (1.568) & \\
\hline \multirow[t]{2}{*}{$4 \times 200 m$ freestyle relay } & 565.290 & 577.788 & *** \\
\hline & $(1.662)$ & $(2.448)$ & \\
\hline \multicolumn{4}{|l|}{ Males } \\
\hline \multirow[t]{2}{*}{$4 \times 100 m$ freestyle relay } & 231.546 & 237.638 & *** \\
\hline & $(0.803)$ & $(0.690)$ & \\
\hline \multirow[t]{2}{*}{$4 \times 100 m$ medley stroke relay } & 260.680 & 265.148 & $* * *$ \\
\hline & $(0.849)$ & $(0.899)$ & \\
\hline \multirow[t]{2}{*}{$4 \times 200 m$ freestyle relay } & 509.893 & 522.185 & *** \\
\hline & $(1.548)$ & $(1.915)$ & \\
\hline
\end{tabular}

Notes: $(a)^{\star \star *}$ denotes significance at the $1 \%$ level.

(b) Values in parentheses are the standard errors.

\subsection{Peer and Superstar Effects on Performance in Relay Teams}

There are two econometric problems to be addressed when further analyzing the peer

\footnotetext{
5 It needs to be noted that the effect of a superstar team here is still different from the results of Brown. Brown (2011) identifies Tiger Woods as a superstar and not every year's winner of a tournament. For the sake of convenience, we use terms such as the effects of a superstar, the superstar effects, and super team effects hereafter.
} 
effects. First of all, multiple observations per individual in these three years imply that there is unmeasured and unobserved heterogeneity (beyond the age, weight, and height measures) that is confounding the results. Fixed and random effects models are able to mitigate this problem. Second, in the NHSA swimming races, all swimmers compete with each other in the single-elimination competitions. This means that swimmers are not facing random swimmers, but swimmers that are very much like them. Therefore, the sample selection biases induced by the nonrandom process for competitors in a race are also considered in the regressions.

The results of the peer effects on an athlete's performance in the relay teams are presented in Tables 4 and 5. In Table 4, the $X^{2}$ value of the Breusch-Pagan (B-P) test $(=0.74)$ does not reject the null hypothesis of homoskedasticity. Therefore, the results of the OLS regression are supported. Moreover, the Breusch and Pagan Lagrangian multiplier $(L M)$ test $(=153.76)$ rejects the null hypothesis of the absence of an unobserved effect. The random effects (RE) model is supported. In the tests of the selectivity effect, the Mills' ratio statistic $(\lambda=4.24)$ rejects the null hypothesis of an independent Probit model for the selection equation, and supports the Heckman Selection Model.

Table 4 Regression Results of Peer Effects on Male Swimmers' Performance in Relay Teams

\begin{tabular}{|c|c|c|c|c|c|c|}
\hline \multirow{2}{*}{$\begin{array}{l}\text { Male } \\
\text { VARIABLES }\end{array}$} & \multirow[t]{2}{*}{ Pooled OLS } & \multirow[t]{2}{*}{ Pooled WLS } & \multirow[t]{2}{*}{ RE Model } & \multirow[t]{2}{*}{ FE Model } & \multicolumn{2}{|c|}{ Heckman Selection Model } \\
\hline & & & & & $2^{\text {nd }}$ stage & select \\
\hline \multirow[t]{2}{*}{ AvgTime $_{-i}$} & $0.21^{* \star *}$ & $0.21^{* \star *}$ & 0.065 & 0.048 & $0.27^{\star \star \star}$ & \\
\hline & $(0.058)$ & $(0.043)$ & $(0.066)$ & $(0.089)$ & $(0.054)$ & \\
\hline \multirow[t]{2}{*}{ AvgTime $_{i}$} & $1.08^{\star \star \star}$ & $1.08^{\star * \star}$ & $1.19^{\star \star \star}$ & $1.71^{\star * \star}$ & $1.28^{\star \star \star}$ & \\
\hline & $(0.24)$ & $(0.21)$ & $(0.39)$ & $(0.40)$ & $(0.23)$ & \\
\hline \multirow[t]{2}{*}{ SDTime $_{i}$} & $0.61^{* * *}$ & $0.61^{* * *}$ & 0.098 & -0.14 & $0.68^{\star * *}$ & \\
\hline & $(0.20)$ & $(0.16)$ & $(0.22)$ & $(0.23)$ & $(0.20)$ & \\
\hline \multirow[t]{2}{*}{ Star $_{1}$} & -1.55 & -1.55 & 2.21 & $3.35^{\star *}$ & -1.62 & \\
\hline & $(1.23)$ & $(1.21)$ & $(1.43)$ & $(1.39)$ & $(1.21)$ & \\
\hline \multirow[t]{2}{*}{ Age } & $-2.79^{\star \star *}$ & $-2.79^{\star \star *}$ & $-9.99^{\star \star *}$ & $-13.9^{* * *}$ & & $0.27^{\star \star \star}$ \\
\hline & $(0.75)$ & $(0.87)$ & $(2.42)$ & $(3.20)$ & & $(0.032)$ \\
\hline \multirow[t]{2}{*}{ Height } & $-0.71^{\star \star \star}$ & $-0.71^{\star \star \star}$ & 0.63 & 0.84 & $-0.71^{\star \star \star}$ & 0.012 \\
\hline & $(0.27)$ & $(0.23)$ & $(0.49)$ & $(0.46)$ & $(0.26)$ & $(0.0094)$ \\
\hline \multirow[t]{2}{*}{ Weight } & $0.51^{* \star *}$ & $0.51^{* * \star}$ & 0.018 & 0.36 & $0.42^{* *}$ & -0.0051 \\
\hline & $(0.18)$ & $(0.11)$ & $(0.37)$ & $(0.49)$ & $(0.17)$ & $(0.0074)$ \\
\hline PRELIMS & $7.03^{\star \star \star}$ & $7.03^{\star \star \star}$ & $4.03^{\star \star \star}$ & $4.01^{\star \star *}$ & $7.24^{\star \star \star}$ & \\
\hline
\end{tabular}


RaceType

Year

Constant

Observations

Censored obs

Number of schools

(Pseudo) $\mathrm{R}^{2}$

0.998

Breusch-Pagan test $\quad 0.74$

Hausman test

LM test $\left(\bar{\chi}^{2}\right)$

Mills' ratio $(\lambda)$

yes yes

yes

yes

yes

yes

yes

$248^{* * *}$

$205^{\star *}$

yes

188

(99.9)

(93.0)

130

130

2,248

130

14

14

2,118

$175^{\star \star *}$

$-8.67^{\star \star \star}$

43.9)

2,248

14

0.998

$153.76^{* * *}$

Notes: (a) ${ }^{* *}$ denotes significance at the $1 \%$ level and ${ }^{* *}$ denotes significance at the $5 \%$ level.

For the inter-team and intra-team peer effects on the performance of males in a relay

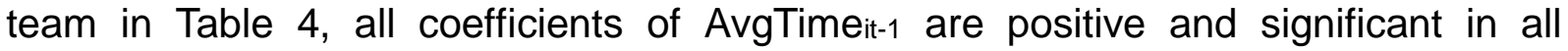
regressions. AvgTime-it-1 and SDTime it-1 are significantly and positively related to a swimming team's time in seconds in all regressions except for the fixed effects (FE) and RE models. The evidence here indicates that a swimmer's speed is influenced by

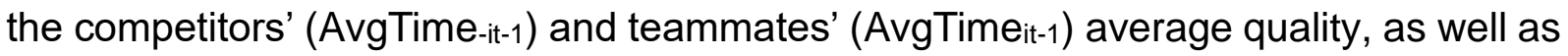
the teammates' relative quality (SDTime ${ }_{i t-1}$ ).

In the analysis of the male swimmer's performance in a relay team, the evidence of inter-team peer effects supports a positive peer effect from the competitors on a relay team's performance. A one unit decrease in the average time of the participants indicates that there are better competitors in a race and this will result in a shorter time (e.g., 0.27 seconds less in the Heckman Selection Model) for a swimming relay team in a race. As to the intra-team peer effects, the evidence of AvgTime it-1 $_{1}$ also supports a positive peer effect from teammates on relay team performance. A one-unit decrease in the average time of the members in a team represents better teammates in a game and will result in a shorter time (e.g., 1.28 seconds less in the Heckman Selection Model) for a relay team in a race. This part of the results corresponds to Depken and Haglund (2011). Moreover, in the paper, the main findings related to peer effects in relay races indicate that a foolish teammate does more damage in terms of the overall time (+1.28 seconds) than a foolish opponent (+0.27 seconds). 
The evidence for SDTime it- 1 indicates that a dispersed-human-capital team induces a longer time. A race with average quality teammates leads to a male relay team achieving a shorter time. This corresponds to the findings in Depken and Haglund (2011) that greater disparity in team member quality increases NCAA relay team times, and Franck and Nüesch (2010) argue that disparity in talent decreases the likelihood of winning a German soccer game in the short run.

As for the effects of a superstar on a male swimming team's performance, the coefficients of Star ${ }_{1}$ are significant and positively related to team performance in the regressions of the FE model in Table 4. The results indicate that a team's performance is affected by the existence of a high-ability swimming team. In terms of the superstar effect in these tournaments, on average, male relay teams' times are approximately 3.35 seconds slower when last year's champion team participates, relative to when the team is absent in the estimation of FE model. The findings support previous research (e.g., Brown, 2011; Tanaka \& Ishino, 2012).

As regards the peer effects on female swimmers' performance in a relay team, the results are presented in Table 5. Both coefficients of AvgTime-it-1 and SDTime it- $1_{\text {are }}$ significantly negative in all regressions. AvgTimeit-1 is significantly and positively related to a swimming team's time in seconds in all regressions. The evidence of inter-team peer effects supports a negative peer effect from competitors on relay team performance. Better competitors in a race will result in a slower time (e.g., 0.52 more seconds in the Heckman Selection Model) for a swimming relay team in a race. As to the intra-team peer effects, the evidence of AvgTimeit-1 also supports a positive peer effect from teammates on relay team performance. Better teammates in an event will result in a shorter time (e.g., 3.39 seconds in the Heckman Selection Model) for a relay team in a race. In this paper, the main findings of peer effects in female relay races indicate that a foolish teammate does more harm $(+3.39$ seconds $)$ than a brilliant opponent (+0.52 seconds).

Table 5 Regression Results of Peer Effects on Female Swimmers' Performance in Relay Teams

\begin{tabular}{|c|c|c|c|c|c|c|}
\hline \multirow{2}{*}{$\begin{array}{l}\text { Female } \\
\text { VARIABLES }\end{array}$} & \multirow[t]{2}{*}{ Pooled OLS } & \multirow[t]{2}{*}{ Pooled WLS } & \multirow[t]{2}{*}{ RE Model } & \multirow[t]{2}{*}{ FE Model } & \multicolumn{2}{|c|}{ Heckman Selection Model } \\
\hline & & & & & $2^{\text {nd }}$ stage & select \\
\hline \multirow[t]{2}{*}{ AvgTime $_{-i}$} & $-0.54^{* \star *}$ & $-0.54^{* \star *}$ & $-0.54^{* * *}$ & $-0.59^{\star * *}$ & $-0.52^{* * *}$ & \\
\hline & $(0.14)$ & $(0.090)$ & $(0.14)$ & $(0.13)$ & $(0.13)$ & \\
\hline \multirow[t]{2}{*}{ Avg Time $_{i}$} & $3.32^{\star \star \star}$ & $3.32^{\star \star \star}$ & $3.32^{\star \star \star}$ & $3.85^{\star \star \star}$ & $3.39^{\star \star \star}$ & \\
\hline & $(0.20)$ & $(0.24)$ & $(0.20)$ & $(0.31)$ & $(0.18)$ & \\
\hline SDTime $_{i}$ & $-1.56^{* * *}$ & $-1.56^{\star \star *}$ & $-1.56^{\star \star *}$ & $-2.37^{\star * *}$ & $-1.60^{* * *}$ & \\
\hline
\end{tabular}




\begin{tabular}{|c|c|c|c|c|c|c|}
\hline & $(0.28)$ & $(0.25)$ & $(0.28)$ & $(0.30)$ & $(0.27)$ & \\
\hline \multirow[t]{2}{*}{ Star $_{1}$} & $-2.88^{\star *}$ & $-2.88^{*}$ & $-2.88^{* *}$ & $-3.57^{\star *}$ & $-3.36^{\star * *}$ & \\
\hline & $(1.43)$ & (1.52) & $(1.43)$ & $(1.57)$ & $(1.30)$ & \\
\hline \multirow[t]{2}{*}{ Age } & -0.85 & -0.85 & -0.85 & $-11.0^{\star \star \star}$ & & $0.19^{* \star \star}$ \\
\hline & $(0.63)$ & $(0.91)$ & $(0.63)$ & $(1.87)$ & & $(0.030)$ \\
\hline \multirow[t]{2}{*}{ Height } & $-0.99^{\star *}$ & $-0.99^{\star *}$ & $-0.99^{\star *}$ & $-2.76^{\star \star \star}$ & $-1.03^{\star *}$ & $0.027^{\star \star}$ \\
\hline & $(0.43)$ & $(0.40)$ & $(0.43)$ & $(0.43)$ & $(0.41)$ & $(0.011)$ \\
\hline \multirow[t]{2}{*}{ Weight } & 0.32 & 0.32 & 0.32 & $2.30^{\star \star \star}$ & 0.38 & -0.0063 \\
\hline & $(0.37)$ & $(0.35)$ & $(0.37)$ & $(0.35)$ & $(0.35)$ & $(0.0087)$ \\
\hline \multirow[t]{2}{*}{ PRELIMS } & $10.6^{\star \star \star}$ & $10.6^{\star \star \star}$ & $10.6^{\star \star \star}$ & $9.91^{\star \star \star}$ & $10.2^{\star \star \star}$ & \\
\hline & $(1.95)$ & $(1.49)$ & $(1.95)$ & $(1.59)$ & $(1.83)$ & \\
\hline RaceType & yes & yes & yes & yes & yes & \\
\hline Year & yes & yes & yes & yes & yes & \\
\hline \multirow[t]{2}{*}{ Constant } & $345^{\star \star \star}$ & $345^{\star * \star}$ & $345^{\star \star \star}$ & $647^{* \star *}$ & $322^{* \star *}$ & $-9.28^{\star \star \star}$ \\
\hline & $(68.2)$ & $(54.8)$ & $(68.2)$ & (73.2) & $(65.0)$ & $(1.60)$ \\
\hline Observations & 119 & 119 & 119 & 119 & 1,950 & 1,950 \\
\hline Censored obs & & & & & 1,831 & \\
\hline Number of schools & & & 9 & 9 & & \\
\hline (Pseudo) $R^{2}$ & 0.999 & 0.999 & & & & \\
\hline Breusch-Pagan test & 0.17 & & & & & \\
\hline Hausman test & & & & $95.08^{* \star *}$ & & \\
\hline LM test $\left(\bar{\chi}^{2}\right)$ & & & 0.00 & & & \\
\hline \multirow[t]{2}{*}{ Mills' ratio $(\lambda)$} & & & & & & 1.56 \\
\hline & & & & & & $(2.04)$ \\
\hline
\end{tabular}

Notes: $(a)^{\star * *}$ denotes significance at the $1 \%$ level, ** denotes significance at the $5 \%$ level, and * denotes significance at the $10 \%$ level.

The evidence for SDTime it-1 indicates that a dispersed-human-capital team induces a shorter time. A race with dispersed quality teammates leads to a relay team achieving a shorter time. Less-good swimming females benefit from a learning effect from their excellent peers. This corresponds to the findings in Franck and Nüesch (2010) that talent disparity decreases the likelihood of winning a German soccer game in the long run.

As for the effects of a superstar on a female swimming team's performance, the coefficients of Star 1 are significant and negatively related to team performance in all regressions in Table 5 . The results indicate that a female team's performance is 
affected by the existence of a high-ability swimming team. On average female relay teams' times are approximately 3.36 seconds faster when last year's champion team participates, relative to when such a team is absent in the estimation of the Heckman Selection model. These findings do not support previous research on PGA tournaments.

As for the control variables, in Tables 4 and 5 the signs of all coefficients for females and males are consistent. The coefficients of age and height are negatively significant. The coefficient of weight in the FE model is positively significant. Regarding these relay swimmers, older, taller, and thinner student athletes swim faster. The coefficients of PRELIMS are positively and significantly related to a swimming team's performance.

${ }^{6}$ Compared with finals, a relay team's times are approximately 4.03 seconds slower on average in preliminary races in the estimation of the RE Model regression.

\subsection{Heckman Selection Model for Panel Data}

To account for possible unobserved individual effects and the issue of a non-random process in team formation at the same time, the regressions of the selection model for panel data proposed by Hsiao (2003) are used. ${ }^{7}$ Table 6 presents the results. All of the signs of the peer effects and a super-team effect for Models both with and without clustering a player's identity are consistent with the results in Tables 4 and 5 . All of these results reinforce previous findings.

Table 6 Regression Results of Peer Effects on Performance in Heckman Selection Model for Panel Data

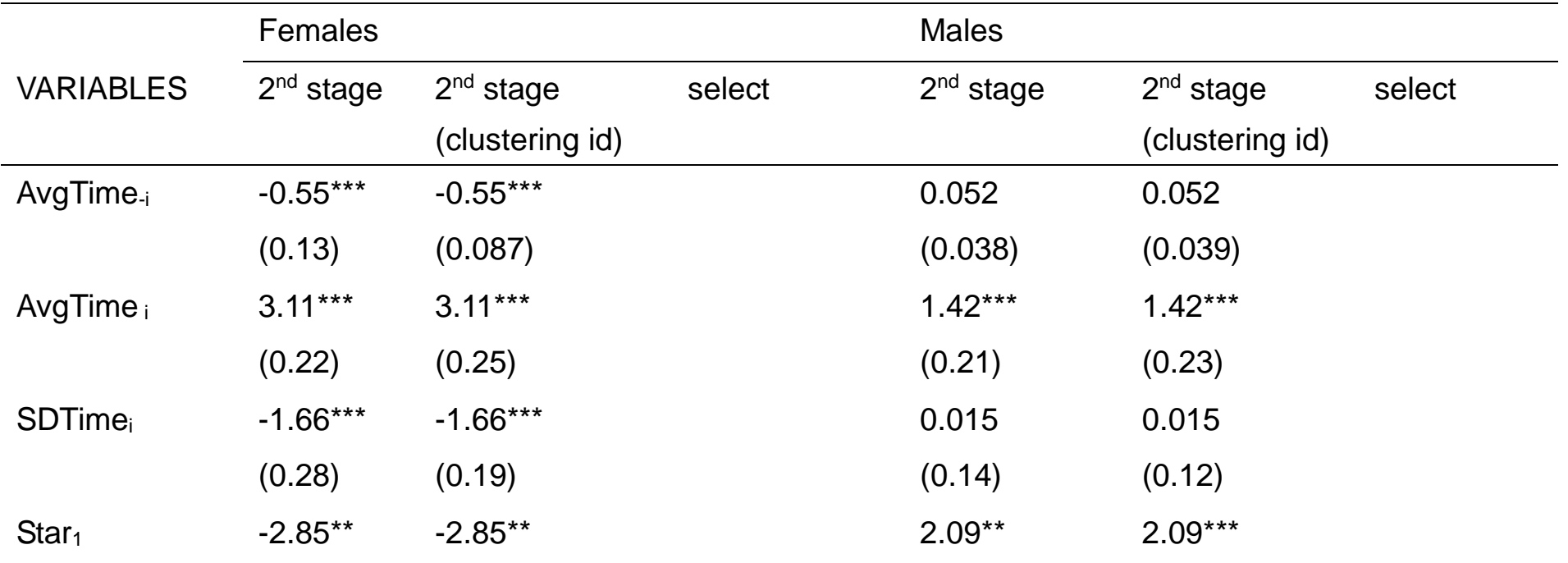

\footnotetext{
${ }^{6}$ In the relay races, there are no contests against a clock. Therefore, the dummy for finals against a clock (CFINALS) is not included in the regressions.

7 Hsiao (2003) in particular picks up heterogeneity and selection as the two major sources of bias in panel data analysis.
} 
(1.38) (1.29)

Age

$(0.83)$

Height

$-0.94^{\text {* }}$

Weight

0.40

PRELIMS

$11.0^{* * *}$

$\ln \sigma_{v}^{2}$

(1.01)

(0.39)

0.40

(0.31)

(1.12)
(0.84)

0.0023

(0.020)

$-0.94^{* *}$

$11.0^{* * *}$

(1.07)

(0.34)

(0.37)

$3.93^{* * *}$

(0.73)
0.011

(0.0084)

$-0.0034$

(0.0071)

(0.071)

$-1.22^{* * *}$

$(0.20)$
(0.78)

$-10.2^{* * *}$

0.013

$(0.017)$

(0.90)

$-0.00088$

$(0.0051)$

0.42

0.00021

(0.0041)

(0.37)

$3.93^{* * *}$

(0.56)

\begin{tabular}{lllllll} 
RaceType & yes & yes & & yes & yes & \\
Year & yes & yes & & yes & yes & \\
Constant & $393^{* *}$ & $393^{* * *}$ & -1.95 & $-176,940^{* * *}$ & $-176,940^{* *}$ & -0.30 \\
& $(113)$ & $(112)$ & $(1.21)$ & $(56,023)$ & $(79,477)$ & $(0.77)$ \\
\hline Observations & 119 & 119 & 3,327 & 130 & 130 & 3,854 \\
Number of id & 44 & 44 & 442 & 66 & 66 & 614 \\
Hausman test & 0.78 & & & $37.79^{* * *}$ & & \\
LM test $\left(\bar{\chi}^{2}\right)$ & 0.17 & & & $3.28^{* *}$ & & \\
Likelihood-rati & & & $97.40^{\star * *}$ & & & \\
o test of & & & & & & \\
$\rho=0\left(\bar{\chi}^{2}\right)$ & & & & & & \\
\hline
\end{tabular}

Notes: $(a)^{\star \star \star}$ denotes significance at the $1 \%$ level, ${ }^{\star \star}$ denotes significance at the $5 \%$ level, and ${ }^{\star}$ denotes significance at the $10 \%$ level.

In Table 6, the first three columns are the results of peer effects and a star-team effect on female performance. Taking the results of the female relay team as an example, in the tests of the selectivity effect in the third column, the statistic of the likelihood-ratio test of $\rho(=97.4)$ rejects the null hypothesis of the unimportance of a panel-level variance component. The panel Tobit estimators are better than the pooled estimators. Each coefficient of AvgTime-i, SDTime ${ }_{i}$ and Star $_{1}$ is significantly negative in the regressions of the Heckman Selection Model for panel data. AvgTimei is significantly and positively related to a swimming team's time in seconds. The evidence of inter-team peer effects supports a negative peer effect of competitors on relay team performance. As for the intra-team peer effects, the evidence of AvgTimeit-1 also supports a positive peer effect from teammates on relay team performance. Peer 
effects in female relay races indicate that a foolish teammate does more harm $(+3.11$ seconds) than a brilliant opponent (+0.55 seconds) in the estimation of the Heckman Selection Model for panel data clustering a player's id. That is, a low-quality performance of a teammate has a detrimental effect on the performance of the others, because affective negativity spread contagiously to teammates (Hatfield, Cacioppo, \& Rapson's,1994; Dimberg \& Ohman, 1996; Barsade, 2002).The results of super-team effects on female swimmers' performance in swimming relays are opposite to those on male swimmers' performance. Empirical evidence obtained by Brown (2011) and Tanaka and Ishino (2012) has suggested that the response to pressure may cause the performance of some competitors to decline, particularly in the case of high-ability individuals. However, our findings for female relays teams suggest that the response to pressure from a high-ability swimmer causes the performance of some competitors to improve rather than decline. In social psychology, Baumeister and Showers (1986) have proposed that self-confidence for the task at hand, which may be positively correlated with ability, can counterbalance the debilitating effects of stress in some circumstances. Therefore, self-confidence has a positive effect on performance under pressure, suggesting a possible explanation for improving performance.

\section{CONCLUSIONS}

This paper looks at the effects of the quality of both competitors and teammates on team performance in multi-stage swimming competitions. In the analysis of peer effects on team performance in female relays, the results of the inter-team peer effect from competitors support a negative peer effect on team performance. The results of the intra-team peer effects support a positive peer effect from teammates on team performance. Moreover, the former estimates of the peer effects from competitors are also consistently smaller than the latter ones. According to our estimations, a foolish teammate does more harm (+3.39 seconds) than a brilliant opponent (+0.52 seconds).

As for the analysis of the peer effects on team performance in male relays, the results of the inter-team peer effect from competitors support a positive peer effect on team performance. The results of the intra-team peer effect also support a positive peer effect from teammates on team performance. Moreover, the former estimates of peer effects from competitors are consistently smaller than the latter ones. Based on our estimations, a foolish teammate does more harm (+1.28 seconds) than a foolish opponent (+0.27 seconds). To sum up, both female and male relay swimmers exhibit consistent and significantly positive intra-team peer effects on performance. Therefore, one of our main conclusions is that 'having good friends is always a good thing.' The robustness checks reinforce our conclusions. 
As to the high-ability peer effects on swimmers' performance, the effect of the existence of high-ability swimmers is associated with induced peer performance in female swimming relays but is associated with reduced peer performance in male swimming relays. On average, female swimmers' times are approximately 2.85 seconds faster when last year's winning team participates relative to when it is absent, but male relay team times are approximately 2.09 seconds slower when last year's winning team participates. The latter findings regarding the super-team effect in the male swimming relay teams are opposite to those of Brown (2011) and Tanaka and Ishino (2012).

These findings suggest three important implications. First, peers are an important factor for the individual and team performance in swimming competitions. Our evidence shows that if the competitors in a race are strongerlweaker and if they are racing against one another in the finals, the incentive for better malelfemale performances in swimming relays will be greater. Meanwhile, if a swimmer has stronger teammates, there will also be cause for better team performance. Intra-team and inter-team peer effects are identical for male swimming relay teams, but they counter each other in the case of female swimming relay teams.

Second, in a relay team, the evidence of peer effects based on the relative quality of teammates shows that a male team with average-quality swimmers performs better than a male team with swimmers of varying quality. This suggests that there exists a free-rider problem in the team. That is, a high-quality swimmer causes the other teammates to free ride on his/her merits when their team takes the lead in a race. Meanwhile, swimmers of similar quality in a team usually compete with each other. Higher degrees of competition associated with higher pressure. Cognitive anxiety probably reflects, in part, man athletes' inability to deal with this pressure. Contrarily, female is more likely to seek emotional social support and increasing their performance. This results in a competition effect in a team with average-quality swimmers. While it is a substantial leap to transfer the findings on swimmers' race performances to children's school behavior, our results suggest that in a school there may be a potential benefit in introducing a competition effect to the male classroom by grouping students according to their ability. Conversely, there is a potential upside to introducing a learning effect to a female classroom by bringing in a superstar pupil.

Finally, we find that multi-stage competitions are effective in terms of providing stimulation, and physical characteristics are important. The significance of the Height coefficients confirms and reinforces the relationship between a swimmer's height and performance. These estimations of the marginal effects can provide valuable information for both swimmers and coaches. 


\section{REFERENCES}

Azoulay, P., Zivin, J.G., \& Wang, J. (2010). "Superstar Extinction." Quarterly Journal of Economics, 125(2), p. 549-89. https://doi.org/10.1162/qjec.2010.125.2.549

Astor-Dubin, L., \& Hammen, C. (1984), "Cognitive versus behavioral coping responses of men and women: A brief report." Cognitive Therapy and Research, 8(1), p. 85-90. https://doi.org/10.1007/BF01315101

Baik, K. H. (1994). "Effort levels in contests with two asymmetric players," Southern Economic Journal, 61 (2), p. 367-379. https://doi.org/10.2307/1059984

Barsade, S. G. (2002), "The ripple effect: Emotional contagion and its influence on group behavior." Administrative Science Quarterly, 47(4), p. 644-675. https://doi.org/10.2307/3094912

Baumeister, R. F., \& Showers, C. J., (1986). "A review of paradoxical performance effects: choking under pressure in sports and mental tests." European Journal of Social Psychology, 16, p. 361-383. https://doi.org/10.1002/ejsp.2420160405

Becker, B. E., \& Huselid, M. A. (1992). The incentive effects of tournament compensation systems. Administrative Science Quarterly, 37(2), p. 336-50. https://doi.org/10.2307/2393228

Berg, P., Appelbaum, E., Bailey, T., \& Kalleberg, A. L. (1996). The performance effects of modular production in the apparel industry. Industrial Relations: A Journal of Economy and Society, 35(3), p. 356-73. https://doi.org/10.1111/j.1468-232X.1996.tb00411.x

Blanksby, B. A., Bloomfield, J., Ponchard, M., \& Ackland, T. R. (1986). "The relationship between anatomical characteristics and swimming performance in state age-group championship competitors." Journal of Swimming Research, 2(2), p. 30-36.

Boning, B., Ichniowski, C., \& Shaw, K. (2007), "Opportunity Counts: Teams and the Effectiveness of Production Incentives." Journal of Labor Economics, 25(4), p. 613-50. https://doi.org/10.1086/519539

Brown, J. (2011), "Quitters Never Win: The (Adverse) Incentive Effects of Competing with Superstars." Journal of Political Economy, 119(5), p. 982-1013. https://doi.org/10.1086/663306

Buser, T., Niederle, M., \& Oosterbeek, H. (2014), "Gender, Competitiveness, and Career Choices." The Quarterly Journal of Economics, 129(3), p. 1409-1447. https://doi.org/10.1093/qje/qju009

Carpenter, J. (2007), "Punishing Free-Riders: How Group Size Affects Mutual Monitoring and the Provision of Public Goods." Games and Economic Behavior, 60(1), p. 31-51. https://doi.org/10.1016/j.geb.2006.08.011 
Carver, C.S., Scheier, M.F., \& Weintraub, J.K. (1989), "Assessing coping strategies: A theoretically based approach." Journal of Personality and Social Psychology, 56(2), 267-283. https://doi.org/10.1037/0022-3514.56.2.267

Croson, Rachel, and Uri Gneezy (2009), "Gender Differences in Preferences." Journal of Economic Literature, 47(2), p. 448-474. https://doi.org/10.1257/jel.47.2.448

Depken, C.A. \& Haglund, L.E. (2011), "Peer Effects in Team Sports: Empirical Evidence From NCAA Relay Teams." Journal of Sports Economics, 12(1), p. 3-19. https://doi.org/10.1177/1527002509361192

Dimberg, U., \& Ohman, A. (1996), "Behold the wrath: Psychophysiological responses to facial stimuli." Motivation and Emotion, 20(2), p. 149-182. https://doi.org/10.1007/BF02253869

Durlauf, S. (2004), "Neighborhood effects," In: J.V. Henderson and J-F. Thisse (Eds.), Handbook of Regional and Urban Economics, 4, Amsterdam: Elsevier Science.

Ehrenberg, R. G., \& Bognanno, M. L. (1990). "Do tournaments have incentive effects?” Journal of Political Economy, 98, p. 1307-24. https://doi.org/10.1086/261736

Eriksson, T. (1999). "Executive compensation and tournament theory: Empirical tests on Danish data." Journal of Labor Economics, 17(2), p. 262-80. https://doi.org/10.1086/209920

Franck, E., \& Nüesch, S. (2010), "The effect of talent disparity on team productivity in soccer." Journal of Economic Psychology, 31(2), p. 218-29. https://doi.org/10.1016/j.joep.2009.12.003

Geladas, N.D., Nassis, G.P., \& Pavlicevic, S. (2005), "Somatic and physical traits affecting sprint swimming performance in young swimmers." International Journal of Sport and Medicine, 26, p. 139-44. https://doi.org/10.1055/s-2004-817862

Genakos, C. \& Pagliero, M. (2012), "Interim Rank, Risk Taking and Performance in Dynamic Tournaments." Journal of Political Economy, 120(4), p. 782-813. https://doi.org/10.1086/668502

Glaeser, E.L. \& J. Scheinkman (2001), "Measuring social interactions." In: S. Durlauf and H.P. Young (Eds.), Social Dynamics, Cambridge: MIT Press.

Guryan, J., K. Kroft, \& Notowidigdo, M. J. (2009), "Peer Effects in the Workplace: Evidence from Random Groupings in Professional Golf Tournaments." American Economic Journal: Applied Economics, 1(4), p. 34-68. https://doi.org/10.1257/app.1.4.34

Hamilton, B. H., Nicherson, J. A., \& Owan, H. (2003). "Team incentives and worker heterogeneity: An empirical analysis of the impact of teams on productivity and participation." Journal of Political Economy, 111, p. 465-497. https://doi.org/10.1086/374182 
Hamilton, B. H., Nickerson, J. A., \& Owan, H. (2012). "Diversity and productivity in production teams." Advances in the Economic Analysis of Participatory \& Labor-Managed Firms, 13, p. 99-138. https://doi.org/10.1108/S0885-3339(2012)0000013009

Hatfield, E., Cacioppo, J., \& Rapson, R. L. (1994), "Emotional contagion." New York: Cambridge University Press.

Heckman, J. J. (1979). "Sample selection bias as a specification error." Econometrica 47(1), p. 153-161. https://doi.org/10.2307/1912352

Helmuth, H. S. (1980), "Anthropometric survey of young swimmers." Anthropologischer Anzeiger, 38(1), p. 17-34.

Holmstrom, B. (1979), "Moral Hazard and Observability." The Bell Journal of Economics, 10(1), p. 74-91. https://doi.org/10.2307/3003320

Holmstrom, B. (1982), "Moral Hazard in Teams." The Bell Journal of Economics, 13(2), p. 324-40. https://doi.org/10.2307/3003457

Hsiao, Cheng (2003) "Analysis of Panel Data." Cambridge University Press, p. 9-18. https://doi.org/10.1017/CBO9780511754203

Ichino, A. \& Maggi, G. (2000), "Work Environment and Individual Background: Explaining Regional Shirking Differentials in a Large Italian Firm." Quarterly Journal of Economics, 115(3), p. 1057-90. https://doi.org/10.1162/003355300554890

Ichniowski, C., Shaw, K., \& Gant, J. (2002), "Social Capital and Organizational Change in High-Involvement and Traditional Work Organizations." Journal of Economics \& Management Strategy 11(2), p. 289-328. https://doi.org/10.1111/jems.2002.11.2.289

loannides, Y.M. \& D.L. Loury (2004), "Job information networks, neighborhood effects, and inequality." Journal of Economic Literature, 42, p. 1056-93. https://doi.org/10.1257/0022051043004595

loannides, Y.M. (2012), From Neighborhoods to Nations: The Economics of Social Interactions. Princeton University Press. https://doi.org/10.1515/9781400845385

Jane, W. J. (2015). Peer Effects and Individual Performance Evidence from Swimming Competitions. Journal of Sports Economics, 16(5), p. 531-39. https://doi.org/10.1177/1527002514521429

Knoeber, C. R., \& Thurman, W. N. (1994), "Testing the theory of tournaments: An empirical analysis of broiler production." Journal of Labor Economics, p. 155-179. https://doi.org/10.1086/298354

Lallemand, T., Plasman, R., \& Rycx, F. (2008), "Women and competition in elimination tournaments: Evidence from professional tennis data." Journal of Sports Economics, 9, p. 3-19. 
https://doi.org/10.1177/1527002506296552

Lazear, E. P., \& Rosen, S. (1981). "Rank-order tournaments as optimum labor contracts." Journal of Political Economy, 89, p. 841-864. https://doi.org/10.1086/261010

Lucas, R. E. (1988), "On the mechanics of economic development." Journal of Monetary Economics, 22, p. 3-42. https://doi.org/10.1016/0304-3932(88)90168-7

Main, B. G., O'Reilly III, C. A., \& Wade, J. (1993). "Top executive pay: Tournament or teamwork?" Journal of Labor Economics, 11(4), p. 606-28. https://doi.org/10.1086/298309

Mas, A. \& Moretti, E. (2009), "Peers at Work." American Economic Review, 99(1), p. 112-45. https://doi.org/10.1257/aer.99.1.112

Mei, X. (1989), "The influence of anthropometric measurements and physical qualities on short distance swimming performance." Sports Science, 9(4), p. 21-24.

Moffitt, R. (2001), "Policy interventions low-level equilibria, and social interactions." In: S. Durlauf and P. Young (Eds.), Social Dynamics, Cambridge, MA: MIT Press, p. 45-82.

Niederle, Muriel, and Lise Vesterlund (2011), "Gender and Competition." Annual Review of Economics, 3(1), p. 601-630. https://doi.org/10.1146/annurev-economics-111809-125122

Prat, A. (2002), "Should a team be homogeneous?" European Economic Review, 46, p. 1187-1207. https://doi.org/10.1016/S0014-2921(01)00165-9

Peter R.E. Crocker and Thomas R. Graham (1995), "Coping by Competitive Athletes With Performance Stress: Gender Differences and Relationships With Affect," The Sport Psychologist, 9(3), p. 325-338. https://doi.org/10.1123/tsp.9.3.325

Ptacek, J.T., Smith, R.E., \& Zanas, J. (1992), "Gender, appraisal, and coping: A longitudinal analysis." Journal of Personality, 60(4), p. 747-770. https://doi.org/10.1111/j.1467-6494.1992.tb00272.x

Rosen, S. (1986), "Prizes and Incentives in Elimination Tournaments." American Economic Review, American Economic Association, 76(4), p. 701-715.

Sunde, U. (2009). "Heterogeneity and performance in tournaments: A test for incentive effects using professional tennis data." Applied Economics, 41(25), p. 3199-3208. https://doi.org/10.1080/00036840802243789

Stracke, R., Wolfgang H., Rudolf K. \& Sunde, U. (2015). "Incentives and selection in promotion contests: Is it possible to kill two birds with one stone?,"Managerial and Decision Economics, 36 (5), p. 275-285. https://doi.org/10.1002/mde.2666 
Stone, A.A., \& Neale, J.M. (1984), "New measure of daily coping: Development and preliminary results." Journal of Personality and Social Psychology, 46(4), p. 892-906. https://doi.org/10.1037/0022-3514.46.4.892

Tanaka, R., \& Ishino, K. (2012). "Testing the incentive effects in tournaments with a superstar." Journal of the Japanese and International Economies, 26(3), p. 393-404. https://doi.org/10.1016/j.jjie.2012.05.001

Tim Woodman and Lew Hardy (2003), "The relative impact of cognitive anxiety and self-confidence upon sport performance: a meta-analysis." Journal of Sports Sciences, 21(6), p. 443-457. https://doi.org/10.1080/0264041031000101809 